\title{
DETERMINATION OF REFURBISHMENT PRIORITIES FOR PASSES ON ROAD NETWORK LEVEL
}

\author{
Matej Kušar, Jana Šelih
}

Original scientific paper

Road infrastructure is exposed to several deterioration processes during its use and therefore, its condition has to be monitored throughout its service life. Refurbishment should be planned for structures with inadequate condition. When refurbishment projects are being planned, however, the road managing company needs to take into account also the budget constraint imposed by the financing bodies. The paper presents development of a multi-criteria decision model, to be used in planning and selecting the passes within state road network that intersect a highway section. Criteria on which the model is based are systematically identified and justified, and their relative importance is determined by using the Analytical Hierarchy Process (AHP). The model selects a group of passes spanning over a highway section that yields maximum total utility when the refurbishment projects are executed while keeping the total refurbishment costs below the allocated amount. The applicability of the proposed model is presented for a selected set of passes.

Keywords: bridge; condition rating; knapsack model; multi-criteria decision model; pass; refurbishment; road network

Određivanje prioriteta u obnovi obilaznica na razini cestovne mreže

Izvorni znanstveni članak

Cestovna infrastruktura je izložena raznim procesima koji dovode do njezinog pogoršanja te se stoga njezino stanje mora stalno pratiti. Treba planirati obnovu konstrukcija u neodgovarajućem stanju. Ipak, kod planiranja projekata obnove, društvo za upravljanje cestama mora uzeti u obzir i ograničenja u buđetu od strane financijske službe. U radu se predstavlja razvoj više kriterijskog modela za donošenje odluke koji će se koristiti u planiranju i odabiru obilaznica unutar mreže državnih putova koji presijecaju dio autoputa. Kriteriji na kojima je model zasnovan sistematično su izabrani i opravdani, a njihova se relativna važnost odredila primjenom Analytical Hierarchy Process (AHP). Modelom se odabire grupa obilaznica iznad dijela autoputa koji će biti od maksimalne ukupne koristi kad se završi obnova, a ukupni troškovi ne prijeđu dodijeljeni iznos. Daje se i primjenjivost predloženog modela na odabranom nizu obilaznica.

Ključne riječi: cestovna mreža; model naprtnjače; most; obilaznica; obnova; procjena stanja; više-kriterijski model donošenja odluke

\section{Introduction}

Road infrastructure provides an invaluable service to the society and national economies. It enables transport of goods and mobility of people, and consequently contributes to the socioeconomic growth of the region under consideration. During its operation, the performance of road structures and sections decreases due to a vast number of reasons, which diminishes the usability and safety of the roads. Therefore, the roads within the network need to be regularly maintained and refurbished when required. At the end of the lifecycle of the road section under consideration, when inadequate performance is exhibited, the possibility of demolition of the road under consideration and/or the structures within the section, should be investigated as well.

Within Slovenia, three levels of public road networks, highways, state roads and municipal roads, are distinguished by the legislature [1]. Each network has its own road manager, a different source of funding and the amount of funding, available for the maintenance and refurbishment of the structures and road sections. Road network is comprised of various elements: sections, tunnels, bridges and passes. In addition, passes spanning over the highway are constructed when state, or municipal roads are intersecting the highway. During the operation stage, performance of the structures in the network decreases due to various deterioration processes associated with ageing, environmental exposure, accumulated traffic load, and even natural hazards, such as earthquakes, floods and landslides [2, 3, 4]. Structural design carried out in the design stage, even when carried out by state-of-the-art standards and guidelines cannot protect the structure from deterioration during the operation stage [3]. Contemporary principles of road management require that contingency planning and execution of refurbishment actions on bridges, passes, tunnels and road sections in case of an emergency is limited. Performing refurbishment works on a structure that is severely damaged may also lead to excessively high costs. As a consequence, the condition of the structures within the road network needs to be monitored on a continuous basis [5]. Refurbishment actions should be initiated when the condition of the bridge (usually described by a set of appropriate quantitative indicators) decreases below the pre-defined level. However, due to the fact that funding required for these actions is always limited, it is necessary to prioritize and select the options that are aligned with the road manager's objectives and societal needs. Maintenance and refurbishment programs through which the refurbishment projects are carried out should therefore include both project and network level [6].

Three levels of road networks, community roads, state roads and highways, each with its own managing authority, are distinguished by the Slovenian legislature. Road network managers are faced with specific challenges in cases where two road networks, for example highway and state network, intersect each other. In particular, the highway manager does not wish any perturbation of the highway operation, caused by the refurbishment works, carried out on a group of municipal road passes that span over a certain highway section. Therefore, the highway manager may voluntarily takeover also the refurbishment of such group of structures, ensure funding of these works and decide how to carry out the 
refurbishment. Multi-criteria decision methods can be an extremely useful tool in this process [7].

The purpose of the presented research is to establish a decision model that is to be embedded into the general management system of the company managing the highway infrastructure; i.e. on the network level. The model aims to support the decisions taken within the framework of the refurbishment management of passes spanning over a selected highway section and as such, it is based on several criteria that are systematically identified and justified in the following section. The relative importance assigned to these criteria is determined on the basis of interview with a selected experienced expert, who expressed his priorities in road refurbishment by using Analytical Hierarchy Process [8, 9]. The decision tool is meant to be used by the highway manager. Therefore, the model should take into account the budget constraints that are inevitable when public funds are being used for the refurbishment actions.

By using the proposed decision tool, total utility (benefit) gained through refurbishment of the selected set of passes is maximized, while the overall costs do not exceed the allocated budget.

The paper is organized in the following way: after introduction, the methodology used in the assessment of bridges in Slovenia is briefly presented; criteria to be employed in the model are identified and justified, and their relative importance is determined; the decision model is then established on the basis of the needs of the highway manager; the model is used to determine the set of passes to be refurbished within the next year with the understanding that refurbishment costs for all structures selected should not exceed the allocated amount. Finally, the obtained results are discussed from the viewpoint of their use in practice.

\section{Bridge condition assessment methodology}

In order to initiate the refurbishment of the structures within the road network under consideration, the road managing company needs to collect and analyze data describing the condition of the structures. Bridge condition assessment is a very complex process because a bridge is composed of many structural parts and elements, and the relative importance of these elements is different [10]. Various methods with varying level of reliability, as well as complexity, exist for this purpose [11]. The cost of the majority of these methods prohibits their regular use in routine bridge condition assessment, executed for all bridge structures within network. Visual inspection is accompanied by condition assessment methodology that translates the identified damages and faults into a quantitative measure; condition rating coefficient, $\mathrm{R}$, is, however, cost effective but less reliable $[5,12,13]$. The survey of inspection practices on network level, performed for various countries [14], nevertheless shows that worldwide, the majority of road network managing agencies use this method in their daily work.

The presented research is based on results obtained by the methodology that is routinely used in the Republic of Slovenia for assessing the condition of bridges and passes. This methodology is based on the results of the visual inspection, and it requires that the assessment is carried out for individual structural parts (substructure, superstructure and bridge deck) of the bridge under consideration. The structural parts are further divided into structural elements. The overall condition rating coefficient of the bridge, $R$, is defined as the sum of the partial condition rating coefficients assigned to the individual structural parts

$$
R=R_{\text {sub }}+R_{\text {sup }}+R_{\text {deck }}
$$

where $R_{\text {sub }}, R_{\text {sup }}$ and $R_{\text {deck }}$ are the substructure, superstructure and bridge deck condition rating coefficients, respectively. These structural parts consist of several structural elements; for example, the substructure consists of foundations, abutments, wing walls and other elements [5]. For each damage type, the methodology introduces partial weighting coefficients describing [14]:

- the importance of the element: $K_{1, \mathrm{j}}, j=1, \ldots, n$, where $\mathrm{n}$ is the number of elements of the analysed bridge;

- the intensity of the damage $\mathrm{i}$ upon the element $\mathrm{j}: K_{2, i, j}$, $j=1, \ldots, m$;

- the weight expressing the extent of the damage $\mathrm{i}$ on the element $\mathrm{j}: K_{3, i, j}, j=1, \ldots, r$; and

- the weight emphasizing the urgency of intervention on the element $\mathrm{j}$, due to safety, usability, and durability threat originating from damage $i: K_{4, i, j}$.

$B_{i}$ is the reference value for the identified damage $i$ ( $i$ $=1, \ldots, m ; \mathrm{m}$ is the total number of identified damages).

Condition rating for the damage type $(i)$ and selected element $(j)$ is defined as

$R_{i j}=B_{i} \cdot K_{1, j} \cdot K_{2, i, j} \cdot K_{3, i, j} \cdot K_{4, i, j}$

The overall condition rating value for the structural part under consideration, $R_{\text {str }},(\mathrm{str}=\{\mathrm{sub}, \sup , \operatorname{deck}\})$ is the sum of partial condition ratings:

$$
R_{\mathrm{str}}=\sum_{i=1}^{m} \sum_{j=1}^{n} R_{i, j}=\sum_{i=1}^{m} \sum_{j=1}^{n} B_{i} \cdot K_{1, j} \cdot K_{2, i, j} \cdot K_{3, i, j} \cdot K_{4, i, j}
$$

$n$ is the number of structural elements of the structural part. For example, structural elements of the substructure are foundations, abutments, wing walls etc. The details of the procedure determining the values of the weights $K_{2, i, \mathrm{j}}$, $K_{3, i, j}$ and $K_{4, i, j}(i=1, \ldots, n ; j=1, . ., m)$, can be found in [5, 14 ].

The methodology prescribes that remedial works need to be initiated when the overall condition rating coefficient value, $R$, valid for the overall structure; or the $R_{k}$ ( $k=$ sub; sup; deck) valid for the structural part, exceeds the threshold value.

Typical damage of the superstructure that presents a significant threat to the structural safety is presented in Fig. 1. The exhibited deterioration of the main beam requires immediate intervention. 


\section{Development of the multi-criterion decision model 3.1 Identification of the criteria}

For the particular case under consideration, the decision model is to be developed on the basis of several criteria and their relative importance. The most obvious criterion to be used is the condition rating $R$ that quantifies the deterioration level of the pass under consideration.

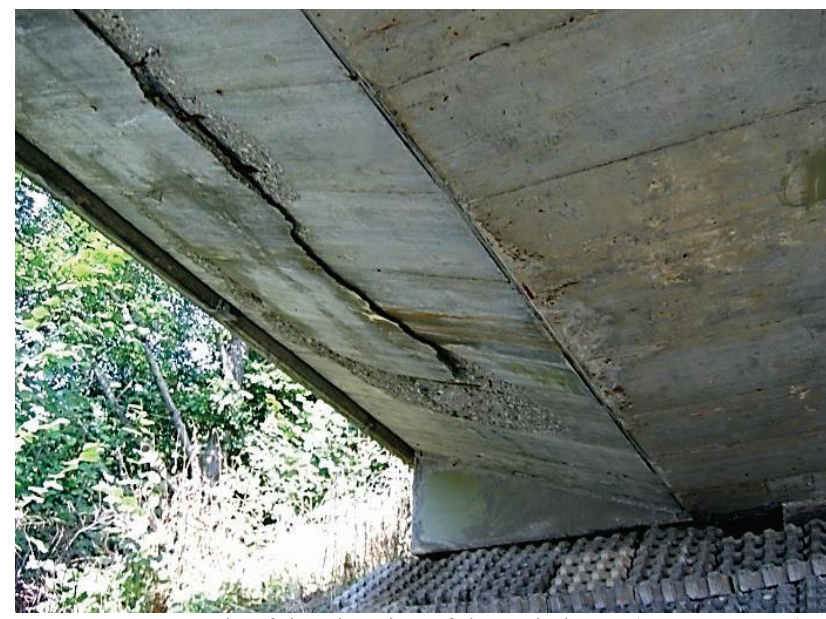

Figure 1 Example of deterioration of the main beam (superstructure) where intervention is urgent.

Age of the pass, $A$, describes, to a certain extent, the functional performance of the bridge (e.g. the dimensions, or number of lanes, complying with contemporary requirements). In addition to the condition rating, the deterioration rate, $D R$, in a given time interval [15] is an important criterion that describes the progress of degradation for the structure under consideration. The values of $D R$ are calculated as the difference of condition rating coefficient values, recorded in the last 2 years, $R_{t 2}$ and $R_{t 1}$, divided by the time interval between two consequent records:

$D R=\left(R_{t 2}-R_{t 1}\right) /\left(t_{2}-t_{1}\right)$.

In addition to the presented criteria of technical nature, criteria that relate to the socio-economic aspect have to be included in the model as well. The limited budget for the refurbishment actions within a certain time period implies that the refurbishment project costs, PC, need to be selected as a criterion within the model as well. Refurbishment project costs consist of the cost of the executed works and costs related to the lane closure that is required during works execution.

User costs are included in the analytical framework of bridge management system as recommended by OECD [16]. When refurbishment takes place, the drivers spend more time travelling due to compulsory speed reduction and closure of one side of the highway (required in order to be able to carry out the refurbishment works on structures above lane closure), or, in other words, lose time due to prolonged travel time, which can be expressed as user, or indirect costs, $I C$ :

$$
I C=\left(\frac{d_{c 1}}{v_{1}}-\frac{d_{c 1}}{v_{0}}\right) \cdot D T V \cdot c_{\mathrm{aver}} \cdot t_{R}
$$

where: $d_{c 1}-$ the length of the closed lane (the length between two consequent openings in the mid-line barrier; $D T V$ - average daily traffic volume for a particular pass location; $t_{R}-$ average expected duration of rehabilitation works (60 days); and $c_{\text {aver }}-$ average net wage per hour in Slovenia (5,90 EUR/h [17].

Moreover, from the manager's as well as drivers' point of view, it is required that the passes selected for refurbishment be analyzed within the context of a string/sequence of structures. In case of refurbishment work executed on one side of the pass, the traffic on the highway lanes below needs to be deviated to the other side of the highway. During deviation planning, it should be kept in mind that deviation of the traffic to the other side of the road is possible only between two consequent mid-line barrier openings. Closing of the lane is associated with costs and often triggers complaints from the users; therefore the highway manager is motivated to carry out refurbishment works as rationally as possible, i.e. on a group of sequential passes between two midline barrier openings simultaneously. Therefore, the potential of grouping several passes during refurbishment is also identified as a criterion. It should be noted that the design of the midline barrier openings on Slovenian highways allows grouping of maximum 3 passes.

The identified criteria are summarized in Tab. 1. Partial utility associated with criteria $R, A, D R$ and $G(j=$ $1,2,3,6)$ increases if the assigned value increases, since old, damaged structures should be refurbished first, while taking into account also the benefit associated with grouping of a string of structures. On the other hand, partial utilities associated with costs $(I C$ and $R P C ; j=4$, 5) decrease if the value assigned to these criteria decreases.

Table 1 Criteria identified as relevant for the decision process.

\begin{tabular}{|l|l|}
\hline$j$ & \multicolumn{1}{|c|}{ CRITERION } \\
\hline 1 & Condition rating, $R(-)$ \\
\hline 2 & Age, $A$ (years) \\
\hline 3 & Grouping, $(G)(-)$ \\
\hline 4 & Indirect costs, $I C$ (EUR), \\
\hline 5 & Refurbishment project costs $R P C($ EUR $)$ \\
\hline 6 & Deterioration rate, $D R(1 /$ years $)$ \\
\hline
\end{tabular}

\subsection{Determination of the relative performance of individual criteria}

The criteria employed in the decision process are not equally important. Determination of their relative importance is a complex task, and is based on preferences and experience of the decision-maker. For the case under consideration, this process was carried out by using Analytical Hierarchy Process (AHP) proposed by [8]. This method is based on the observation of psychologists who argue that individuals compare various items easier when two items (a pair) are compared. A qualified professional, in this particular case a civil engineer with more than 10 years of experience in bridge repair management, was selected to be interviewed in order to provide the pair-wise comparisons of criteria, as required by the AHP. Based on his estimates, a pairwise comparisons matrix, $\boldsymbol{A}$, is formed: 


$$
\begin{gathered}
\boldsymbol{A}=\left(a_{i j}\right)=\left[\begin{array}{cccc}
1 & \frac{w_{1}}{w_{2}} & \cdots & \frac{w_{1}}{w_{m}} \\
\frac{w_{2}}{w_{1}} & 1 & \cdots & \frac{w_{2}}{w_{m}} \\
\vdots & \vdots & \ddots & \vdots \\
\frac{w_{m}}{w_{1}} & \frac{w_{m}}{w_{2}} & \cdots & 1
\end{array}\right] \\
a_{i i}=1, a_{i j}=\frac{w_{i}}{w_{j}}=\frac{1}{a_{j i}}, a_{i j} \neq 0 .
\end{gathered}
$$

$a_{i j}$ is the relative importance of criterion $i$ compared to criterion $j$; and $a_{j i}$ relative importance of criterion $j$ compared to criterion $i$. For the case considered, $m=6$. The selected expert was interviewed, and based on his opinion, the pair-wise matrix (Eq. (6)) for the criteria summarized in Tab. 1 was established (Tab. 2).

Table 2 Pair-wise comparisons matrix, $\boldsymbol{A}$, for the set of identified

\begin{tabular}{|c|c|c|c|c|c|c|}
\hline & $R$ & $A$ & $G$ & $I C$ & $R C$ & $D R$ \\
\hline$R$ & 1,00 & 7,00 & 7,00 & 9,00 & 9,00 & 5,00 \\
\hline$A$ & 0,14 & 1,00 & 0,50 & 2,00 & 2,00 & 0,20 \\
\hline$G$ & 0,14 & 2,00 & 1,00 & 2,00 & 2,00 & 0,20 \\
\hline$I C$ & 0,11 & 0,50 & 0,50 & 1,00 & 1,00 & 0,20 \\
\hline$R C$ & 0,11 & 0,50 & 0,50 & 1,00 & 1,00 & 0,20 \\
\hline$D R$ & 0,20 & 5,00 & 5,00 & 5,00 & 5,00 & 1,00 \\
\hline$\Sigma$ & $\mathbf{1 , 7 1}$ & $\mathbf{1 6 , 0 0}$ & $\mathbf{1 4 , 5 0}$ & $\mathbf{2 0 , 0 0}$ & $\mathbf{2 0 , 0 0}$ & $\mathbf{6 , 8 0}$ \\
\hline
\end{tabular}

The relative importance for the individual criteria was calculated as proposed by [8]. The obtained values are presented in Tab. 3. It is not surprising that the criteria that describe the present and future structural soundness, i.e. condition rating and deterioration rate, are judged to be significantly more important than the other criteria. The calculated consistency index ratio for the listed criteria is $5,8 \%$; therefore, the determined relative importance coefficients can be confidently used in the establishment of the decision model [8].

Table 3 Criteria identified as relevant in the decision process, and their relative importance $\left(w_{j}\right)$ defined by the AHP method (listed in descending order of relative importance)

\begin{tabular}{|c|c|}
\hline CRITERION & $w_{j}$ \\
\hline$R$ & 0,52 \\
\hline$A$ & 0,07 \\
\hline$G$ & 0,08 \\
\hline$I C$ & 0,04 \\
\hline$R C$ & 0,04 \\
\hline$D R$ & 0,24 \\
\hline$\Sigma$ & 1,00 \\
\hline
\end{tabular}

\subsection{Determination of the total utility}

Total utility associated with refurbishment of a selected set of passes, $U_{\text {tot }}$, needs to be maximized in order to obtain efficient use of allocated funds, while the total costs of refurbishment of a group of passes, $C_{\text {tot }}$, have to be kept within budget $\left(C_{\text {alloc }}\right)$. Utility gained by the refurbishment of pass $i, U_{i}$, can be expressed as

$U_{i}=\sum_{i=1}^{6} U_{i j} \cdot w_{j}$
$U_{i j}$ is partial utility value obtained by the refurbishment of the structure (pass) $i$ with respect to the criterion $j$.

Total utility gained by refurbishment of the selected set of structures (passes), $U_{\text {tot }}$, is the sum of utilities for individual passes

$U_{\text {tot }}=\sum_{i=1}^{n}\left(z_{i} \cdot U_{i}\right)$

and defines the objective function of the problem under consideration; i.e. the selected group of passes to be refurbished should result in maximum total utility score. $\boldsymbol{Z}=\left(z_{i}\right)$ is the decision vector defined as

$z_{i} \in\{0 ; 1\}$

$z_{i}=1$ if pass $\mathrm{i}$ is selected for refurbishment, else $z_{i}=0 . C_{i}$ is the cost of refurbishment of the structure $i$.

Total refurbishment costs for the set of selected passes, $C_{\text {tot }}$, are determined as

$C_{\mathrm{tot}}=\sum_{i=1}^{n}\left(C_{i} \cdot z_{i}\right)$

Due to the limited budget allocated for the refurbishment within a certain time period, a constraint is introduced for the total costs associated with the refurbishment of the selected portfolio of passes:

$C_{\text {tot }}=\sum_{i=1}^{n}\left(C_{i} \cdot z_{i}\right)<C_{\text {alloc }}$

$C_{\text {alloc }}$ is the allocated budget for the given time period (typically 1 year).

The optimization problem defined by the Eqs. (7) $\div$ (11) can be considered as a knapsack problem [18] that can be solved by using the function SOLVER of the MS Excel software.

Normalized utility values, $U_{i j}$, related to criteria $R, A$, $G$ and $D R(j=1,2,3,6)$ are obtained by using the expression

$U_{i j}=\frac{1+9 \cdot\left(f_{i j}-f_{\min , j}\right)}{\left(f_{\max , j}-f_{\min , j}\right)}$

Normalized utility values, $U_{i j}$, related to criteria $R C$ and $I C(j=4,5)$ are determined as

$U_{i j}=\frac{10-9 \cdot\left(f_{i j}-f_{\min , j}\right)}{\left(f_{\max , j}-f_{\min , j}\right)}$

The Eqs. (12) and (13) imply that benefit gained by the selection of the group of structures decreases when project and indirect costs increase, while it increases when age, condition rating, deterioration rate and possibility of grouping increase. 


\section{Case study}

27 passes bridge the selected highway section within the Slovenian highway network; its length is $59 \mathrm{~km}$. The data describing these passes with respect to the criteria identified as relevant are collected in Tab. 4. Despite the fact that the passes under consideration are relatively uniform from the viewpoint of age, they vary significantly both in terms of condition rating and deterioration rate.

Table 4 Actual partial utility values for the group of passes under consideration, with respect to the selected criteria. Shaded fields (column G) indicate groups of passes where the refurbishment can be carried out simultaneously, and can thus be grouped, within the process, by joint lane closure.

\begin{tabular}{|c|c|c|c|c|c|c|}
\hline \multirow[b]{2}{*}{$\begin{array}{l}\text { Pass } \\
\text { no., } i\end{array}$} & \multicolumn{6}{|c|}{ Actual values, $f_{i j}$} \\
\hline & $R /-$ & $\begin{array}{c}A / \\
\text { years }\end{array}$ & $G /-$ & $I C /$ EUR & $R C /$ EUR & $\begin{array}{c}D R / \\
1 / \text { year }\end{array}$ \\
\hline 1 & 4,29 & 33 & 1 & 250006 & 401370 & 0,18 \\
\hline 2 & 9,02 & 33 & 3 & 492423 & 411916 & 0,30 \\
\hline 3 & 6,61 & 31 & 3 & 492423 & 454886 & 0,08 \\
\hline 4 & 9,03 & 32 & 3 & 471226 & 481644 & 0,10 \\
\hline 5 & 9,92 & 32 & 1 & 323207 & 387686 & 0,27 \\
\hline 6 & 6,78 & 31 & 1 & 478721 & 401370 & 0,12 \\
\hline 7 & 5,45 & 31 & 1 & 492961 & 339922 & 0,09 \\
\hline 8 & 12,57 & 31 & 1 & 492961 & 385245 & 0,19 \\
\hline 9 & 11,61 & 31 & 1 & 254408 & 385245 & 0,02 \\
\hline 10 & 12,57 & 31 & 1 & 268744 & 339922 & 0,37 \\
\hline 11 & 9,51 & 31 & 1 & 267864 & 560218 & 0,05 \\
\hline 12 & 13,74 & 31 & 2 & 269750 & 325541 & 0,28 \\
\hline 13 & 4,77 & 31 & 2 & 269750 & 401370 & 0,07 \\
\hline 14 & 11,89 & 31 & 2 & 40014 & 481644 & 0,18 \\
\hline 15 & 15,01 & 31 & 2 & 98301 & 401370 & 0,35 \\
\hline 16 & 6,29 & 31 & 1 & 352788 & 339922 & 0,27 \\
\hline 17 & 10,17 & 31 & 3 & 315576 & 454886 & 0,18 \\
\hline 18 & 9,87 & 31 & 3 & 390713 & 476292 & 0,15 \\
\hline 19 & 5,27 & 31 & 3 & 390713 & 375222 & 0,27 \\
\hline 20 & 6,96 & 31 & 1 & 337043 & 375222 & 0,24 \\
\hline 21 & 7,37 & 31 & 1 & 343979 & 411916 & 0,11 \\
\hline 22 & 9,11 & 31 & 2 & 369575 & 428128 & 0,08 \\
\hline 23 & 9,83 & 31 & 2 & 369575 & 470069 & 0,02 \\
\hline 24 & 11,84 & 31 & 2 & 438290 & 806091 & 0,06 \\
\hline 25 & 14,89 & 31 & 2 & 438290 & 1434266 & 0,16 \\
\hline 26 & 18,05 & 31 & 1 & 422108 & 473799 & 0,20 \\
\hline 27 & 10,07 & 31 & 1 & 524271 & 473799 & 0,08 \\
\hline MAX & 18,05 & 33 & 3 & 524271 & 1434266 & 0,37 \\
\hline MIN & 4,29 & 31 & 1 & 40014 & 325541 & 0,02 \\
\hline $\begin{array}{c}\Sigma \\
(\text { EUR) }\end{array}$ & & & & 9655680 & 12678961 & \\
\hline
\end{tabular}

The openings in the mid-line barrier allow a joint lane closure and consequent grouping of refurbishment projects/facilities within several sections. The following groups of passes can be created when refurbishment works are planned:

a) passes no. $2,3,4$;

b) passes no. $17,18,19$;

c) no. 7 and 8 ;

d) no. 12 and 13 ;

e) no. 22 and 23; and

f) no. 24 and 25 .

The decision model defined in Section 3 is used to identify the set of passes (out of the whole group of 27 passes considered) that will be refurbished within the next year. Total available budget for refurbishment $\left(C_{\text {alloc }}\right)$, in this period equals 10 million EUR, i.e. less than the amount required for refurbishment of all structures under consideration, defined in Tab. 4 (12,68 million EUR). The height of the allowable indirect costs (added to the total refurbishment costs) that account for the drivers' time lost due to the travelling speed reduction is taken as 2 million EUR.

The normalised partial utility values, determined by Eqs. (12) and (13) are given in Tab. 5.

Table 5 Normalised utility values for the group of passes under consideration, with respect to the selected criteria. Shaded fields (column G) indicate groups of passes where the refurbishment can be carried out simultaneously, and can thus be grouped, within the process, by joint lane closure. Normalised values are determined by Eqs. (12) and (13).

\begin{tabular}{|c|c|c|c|c|c|c|}
\hline \multirow{2}{*}{$\begin{array}{c}\text { Pass no., } \\
i\end{array}$} & \multicolumn{6}{|c|}{ Normalised values, $U_{i j}$} \\
\hline & $R^{\prime}$ & $A^{\prime}$ & $G^{\prime}$ & $I C^{\prime}$ & $R C^{\prime}$ & $D R^{\prime}$ \\
\hline 1 & 1 & 10,00 & 1,00 & 6,10 & 9,38 & 5,93 \\
\hline 2 & 4,09 & 10,00 & 10,00 & 1,59 & 9,30 & 2,70 \\
\hline 3 & 2,52 & 1,00 & 10,00 & 1,59 & 8,95 & 8,41 \\
\hline 4 & 4,10 & 5,50 & 10,00 & 1,99 & 8,73 & 7,93 \\
\hline 5 & 4,68 & 5,50 & 1,00 & 4,74 & 9,50 & 3,61 \\
\hline 6 & 2,63 & 1,00 & 1,00 & 1,85 & 9,38 & 7,47 \\
\hline 7 & 1,76 & 1,00 & 1,00 & 1,58 & 9,88 & 8,16 \\
\hline 8 & 6,42 & 1,00 & 1,00 & 1,58 & 9,52 & 5,60 \\
\hline 9 & 5,79 & 1,00 & 1,00 & 6,02 & 9,52 & 9,92 \\
\hline 10 & 6,42 & 1,00 & 1,00 & 5,75 & 9,88 & 1,00 \\
\hline 11 & 4,41 & 1,00 & 1,00 & 5,77 & 8,10 & 9,19 \\
\hline 12 & 7,18 & 1,00 & 5,50 & 5,73 & 10,00 & 3,37 \\
\hline 13 & 1,31 & 1,00 & 5,50 & 5,73 & 9,38 & 8,73 \\
\hline 14 & 5,97 & 1,00 & 5,50 & 10,00 & 8,73 & 5,94 \\
\hline 15 & 8,01 & 1,00 & 5,50 & 8,92 & 9,38 & 1,65 \\
\hline 16 & 2,31 & 1,00 & 1,00 & 4,19 & 9,88 & 3,64 \\
\hline 17 & 4,85 & 1,00 & 10,00 & 4,88 & 8,95 & 5,82 \\
\hline 18 & 4,65 & 1,00 & 10,00 & 3,48 & 8,78 & 6,62 \\
\hline 19 & 1,64 & 1,00 & 10,00 & 3,48 & 9,60 & 3,53 \\
\hline 20 & 2,75 & 1,00 & 1,00 & 4,48 & 9,60 & 4,26 \\
\hline 21 & 3,01 & 1,00 & 1,00 & 4,35 & 9,30 & 7,70 \\
\hline 22 & 4,15 & 1,00 & 5,50 & 3,88 & 9,17 & 8,31 \\
\hline 23 & 4,62 & 1,00 & 5,50 & 3,88 & 8,83 & 10,00 \\
\hline 24 & 5,94 & 1,00 & 5,50 & 2,60 & 6,10 & 8,92 \\
\hline 25 & 7,93 & 1,00 & 5,50 & 2,60 & 1,00 & 6,26 \\
\hline 26 & 10,00 & 1,00 & 1,00 & 2,90 & 8,80 & 5,30 \\
\hline 27 & 4,78 & 1,00 & 1,00 & 1,00 & 8,80 & 8,37 \\
\hline
\end{tabular}

Tab. 6 presents the results of the established knapsack decision model (i.e. the set of passes selected to be refurbished), that yield the largest total utility.

From the viewpoint of the decision-maker (network manager), it is important to know the dependence of the total gained utility upon varying values of the budget, and therefore, a parametric study was carried out.

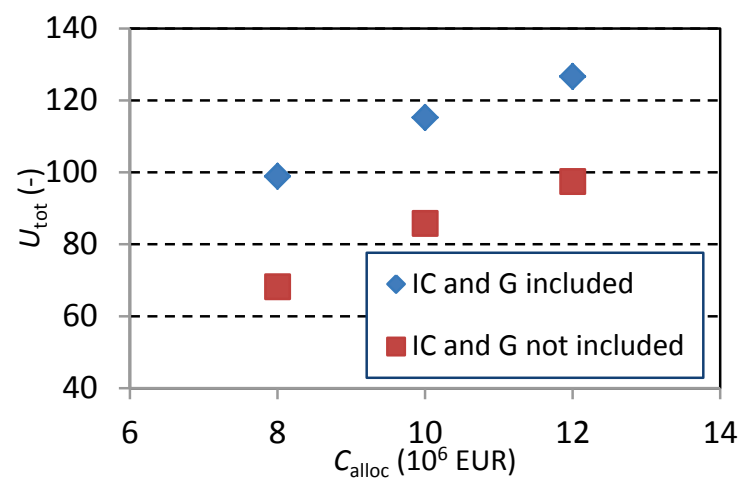

Figure 2 The dependence of the total utility (gained by the refurbishment of the selected passes) upon the budget constraint.

The available budget (i.e. the cost constraint, $C_{\text {alloc }}$ ) is taken as 8, 10 and 12 million EUR. The dependence of the total utility, $U_{\text {tot }}$, obtained by the available budget is 
presented in Fig. 2. Two criteria sets are considered; the first takes into account all 5 criteria (Tab. 3), while the second does not include the indirect costs and the possibility of grouping the passes. It can be seen that despite relatively small relative importance, the inclusion of grouping of passes is significantly influencing the utility result, as it decreases the discomfort of the drivers and optimizes the costs of the lane closure. Further, it can be seen that a small variation of the allocated budget yields significantly increased total utility $U_{\text {tot }}$, gained by the refurbishment of the set of selected passes.

Table 6 Results of the knapsack decision model when available budget of total direct costs $\left(C_{\text {alloc }}\right)$ is 8,10 and $1210^{6} \mathrm{EUR}$; and various decision scenarios are considered: the influence of considering indirect costs and grouping is evaluated (alternatives A0, A1, A2 vs B0, B1,

$\mathrm{B} 2) ; 0=$ structure is not selected for refurbishment; $1=$ structure is selected for refurbishment.

\begin{tabular}{|c|c|c|c|c|c|c|}
\hline & $\mathrm{A} 0$ & A1 & A2 & B0 & B1 & $\mathrm{B} 2$ \\
\hline $\begin{array}{c}C_{\text {alloc }} \\
\left(10^{6} \text { EUR }\right)\end{array}$ & 8 & 10 & 12 & 8 & 10 & 12 \\
\hline$I C$ included & no & no & no & yes & yes & yes \\
\hline$G$ included & no & no & no & yes & yes & yes \\
\hline Str. code $(i)$ & \multicolumn{3}{|c|}{ Dec. vector $z_{i, A}$} & \multicolumn{3}{|c|}{ Dec. vector $z_{i, B}$} \\
\hline 1 & 0 & 1 & 1 & 0 & 0 & 0 \\
\hline 2 & 1 & 1 & 1 & 1 & 1 & 1 \\
\hline 3 & 1 & 1 & 1 & 1 & 1 & 1 \\
\hline 4 & 1 & 1 & 1 & 1 & 1 & 1 \\
\hline 5 & 1 & 1 & 1 & 0 & 0 & 0 \\
\hline 6 & 0 & 1 & 1 & 0 & 0 & 0 \\
\hline 7 & 1 & 1 & 1 & 0 & 0 & 0 \\
\hline 8 & 1 & 1 & 1 & 0 & 0 & 1 \\
\hline 9 & 1 & 1 & 1 & 0 & 1 & 1 \\
\hline 10 & 1 & 1 & 1 & 0 & 0 & 1 \\
\hline 11 & 0 & 0 & 1 & 0 & 1 & 0 \\
\hline 12 & 1 & 1 & 1 & 1 & 1 & 1 \\
\hline 13 & 1 & 1 & 1 & 1 & 1 & 1 \\
\hline 14 & 1 & 1 & 1 & 1 & 1 & 1 \\
\hline 15 & 1 & 1 & 1 & 1 & 1 & 1 \\
\hline 16 & 0 & 1 & 1 & 0 & 0 & 0 \\
\hline 17 & 1 & 1 & 1 & 1 & 1 & 1 \\
\hline 18 & 1 & 1 & 1 & 1 & 1 & 1 \\
\hline 19 & 0 & 1 & 1 & 1 & 1 & 1 \\
\hline 20 & 0 & 1 & 1 & 0 & 0 & 0 \\
\hline 21 & 1 & 1 & 1 & 0 & 0 & 0 \\
\hline 22 & 1 & 1 & 1 & 1 & 1 & 1 \\
\hline 23 & 1 & 1 & 1 & 1 & 1 & 1 \\
\hline 24 & 0 & 0 & 1 & 0 & 1 & 1 \\
\hline 25 & 0 & 0 & 0 & 1 & 1 & 1 \\
\hline 26 & 1 & 1 & 1 & 0 & 0 & 1 \\
\hline 27 & 1 & 1 & 1 & 0 & 0 & 0 \\
\hline$\Sigma$ & 19 & 24 & 26 & 13 & 16 & 18 \\
\hline$U_{t o t}$ & 98,88 & 115,25 & 126,63 & 68,2 & 85,8 & 97,41 \\
\hline $\begin{array}{c}\Sigma C\left(10^{6}\right. \\
\text { EUR })\end{array}$ & 7,99 & 9,88 & 11,24 & 7,92 & 9,95 & 11,5 \\
\hline
\end{tabular}

The network manager should therefore evaluate the influence of the allocated budget upon the achieved total utility as a small variation in the allowed budget could visibly influence the selection of passes to be refurbished, and the associated total utility.

\section{Conclusions}

Managing road infrastructure system is a challenging task. Different structures deteriorate at different rates, due to a wide range of causes, therefore their condition rating needs to be monitored on a regular basis. Due to the limited budget available for refurbishment of these structures, the refurbishment priorities should be clearly identified and justified. The proposed decision model aims to support these decisions on the network level, while taking into account the existing constraints, particularly the ones regarding the available budget.

Application of the model to a case study, presented in the paper, shows that the model has a significant potential in supporting the decisions of the road manager. Another important benefit provided by the use of the model is being able to study the benefit (utility) gained by the refurbishment on network level. For the group of structures under consideration, that need to be located in a sequence within a highway section, the model selects a set of structures to be refurbished. Rational use of public funds is therefore ensured, as required by the Public Procurement legislature. It should be emphasized, however, that the benefit associated with refurbishment of the selected set is determined by using pre-defined criteria and their relative importance, therefore it is clear that future research endeavours should be directed towards establishing methodology that enables systematic identification of the criteria for various cases.

In addition, several experts from various fields who are involved in road management, e.g. maintenance managers, traffic theory specialists, and economists should be involved in the determination of criteria and their relative importance in order to obtain a decision tool that encompasses the needs of key stakeholders. Future research endeavours should be therefore focussed towards establishment of a structured approach for the identification of these experts, since they provide the fundamentals for the decision model. Another important aspect to be studied in the future is extending the proposed decision model to the level of structural parts (i.e. to describe separately substructure, superstructure, bridge deck), as they may deteriorate at various rates, and have consequently various refurbishment needs.

\section{Acknowledgement}

The authors thank Prof. Antonio C. M. Sousa for the review and suggestions to the text. Financial support received by Slovenian Research Agency through Research Programme No P2-0185 is gratefully acknowledged.

\section{References}

[1] Regulation on Roads 2010. Official Gazette of Republic of Slovenia, No. 109/2010, available at http://www.uradnilist.si/1/objava.jsp?urlid $=2010109 \&$ stevilka $=5732$ (In Slovenian)

[2] Šelih, J.; Kne, A; Srdić, A.; Žura, M. Multiple-criteria decision support system in highway infrastructure management. // Transport. 23, 4(2008), pp. 299-305. https://doi.org/10.3846/1648-4142.2008.23.299-305

[3] Frangopol, D. M.; Liu, M. Maintenance and management of civil infrastructure based on condition, safety, optimization and life-cycle cost. // Structure and Infrastructure Engineering. 3, 1(2007), pp. 29-41. https://doi.org/10.1080/15732470500253164

[4] Dong, Y.; Frangopol, D. M.; Saydam, D. Pre-Earthquake Multi-Objective Probabilistic Retrofit Optimization of Bridge Networks Based on Sustainability. // J. of Bridge Engineering. 19, 6(2014), CID: 04014018, https://doi.org/10.1061/(ASCE)BE.1943-5592.0000586 
[5] Kušar, M.; Šelih, J. Analysis of bridge condition on state network in Slovenia. // Građevinar, 66, 9(2014), pp.811822.

[6] Dehghani, M. S.; Flintsch, G.; McNeil, S. Impact of Road Conditions and Disruption Uncertainties on Network Vulnerability. // J. of Infrastructure Systems. 20, 3(2014), CID: 04014015.

[7] Deluka-Tibljaš A.; Karleuša, B.; Dragičević, N. Review of multicriteria-analysis methods application in decisionmaking about transport infrastructure. // Građevinar. 65, 7(2013), pp. 619-631.

[8] Saaty, T. L. Multicriteria Decision Making, Vol. I, The Analytic Hierarchy Process: Planning, Priority Setting, Resource Allocation, 2nd edition, RWS Publications. 1990, $437 \mathrm{p}$.

[9] Rouyendegh, B. D. Developing an integrated AHP and intuitionistic fuzzy TOPSIS methodology. // Technical Gazette. 21, (2014), pp. 1313-1319.

[10] Deng, X.; Hu, Y.; Deng, Y. Bridge Condition Assessment using D Numbers. // The Scientific World Journal. (2014), Article ID 358057, 11 pages.

[11] Gattulli, V.; Chiarmonte, L. Condition Assessment by Visual Inpection for a Bridge Management System. // Computer-Aided Civil and Infrastructure Engineering. 20, (2005), pp. 95-107. https://doi.org/10.1111/j.1467-8667.2005.00379.x

[12] Dirksen, J.; Clemens, F.; Korving, H.; Cherqui, F.; Le Gauffre, P.; Ertl, T.; Plihal, H.; Müller, K.; Snaterse, C. The consistency of visual sewer inspection data. // Structure and Infrastructure Engineering. 9, (2013), pp. 214-228. https://doi.org/10.1080/15732479.2010.541265

[13] Tenžera, D.; Puž, G.; Radić, J. Visual inspection in evaluation of bridge condition. // Građevinar. 64, 9(2012), pp. 717-726. https://doi.org/10.1061/(ASCE)BE.1943-5592.0000123

[14] Kušar, M. Development of Bridge Management System for Roads and Highways, Doctoral Dissertation, University of Ljubljana, 2014. (In Slovenian)

[15] Agrawal, A. K.; Kawaguchi, A.; Chen, Z. Deterioration Rates of Typical Bridge Rates in New York. // J. of Bridge Engineering ASCE. 15, 4(2010), pp. 419-429.

[16] Chapter IV: Infrastructure, available at http://www.oecd.org/sti/transport/roadtransportresearch/185 9501.pdf (accessed Jan. 17, 2015).

[17] Statistical Office of the Republic of Slovenia, 2013.

[18] Kellerer, H.; Pferschy, U.; Pisinger, D. Knapsack Problems, Springer Verlag, 2004.

https://doi.org/10.1007/978-3-540-24777-7

\section{Authors' addresses}

\section{Matej Kušar, Ph.D.}

University of Ljubljana

Faculty of Civil and Geodetic Engineering

Jamova 2, 1000 Ljubljana, Slovenia

E-mail: matej.kusar@fgg.uni-lj.si

\section{Jana Šelih, Ph.D., Assoc.Prof.}

University of Ljubljana

Faculty of Civil and Geodetic Engineering

Jamova 2, 1000 Ljubljana, Slovenia

E-mail: jana.selih@fgg.uni-lj.si 